\title{
Delay of appropriate antibiotic treatment is associated with high mortality in patients with community-onset sepsis in a Swedish setting
}

\author{
Maria Andersson $^{1}$ (D) - Åse Östholm-Balkhed ${ }^{1} \cdot$ Mats Fredrikson $^{2,3} \cdot$ Martin Holmbom $^{1,4}$ - Anita Hällgren ${ }^{1}$. \\ Sören Berg ${ }^{5} \cdot$ Håkan Hanberger ${ }^{1}$
}

Received: 10 December 2018 / Accepted: 1 March 2019 / Published online: 25 March 2019

(C) The Author(s) 2019

\begin{abstract}
Early appropriate antimicrobial therapy is crucial in patients with sepsis and septic shock. Studies often focus on time to first dose of appropriate antibiotics, but subsequent dosing is equally important. Our aim was to investigate the impact of fulfillment of early treatment, with focus on appropriate administration of first and second doses of antibiotics, on 28-day mortality in patients with community-onset severe sepsis and septic shock. A retrospective study on adult patients admitted to the emergency department with community-onset sepsis and septic shock was conducted 2012-2013. The criterion "early appropriate antibiotic treatment" was defined as administration of the first dose of adequate antibiotics within $1 \mathrm{~h}$, and the second dose given with less than $25 \%$ delay after the recommended dose interval. A high-risk patient was defined as a septic patient with either shock within $24 \mathrm{~h}$ after arrival or red triage level on admittance according to the Medical Emergency Triage and Treatment System Adult. Primary endpoint was 28-day mortality. Of 90 patients, less than one in four (20/87) received early appropriate antibiotic treatment, and only one in three (15/44) of the high-risk patients. The univariate analysis showed a more than threefold higher mortality among high-risk patients not receiving early appropriate antibiotic treatment. Multivariable analysis identified early non-appropriate antibiotic treatment as an independent predictor of mortality with an odds ratio for mortality of 10.4. Despite that the importance of early antibiotic treatment has been established for decades, adherence to this principle was very poor.
\end{abstract}

Keywords Sepsis $\cdot$ Septic shock $\cdot$ Antibiotics $\cdot$ Mortality $\cdot$ Emergency department

Electronic supplementary material The online version of this article (https://doi.org/10.1007/s10096-019-03529-8) contains supplementary material, which is available to authorized users.

Maria Andersson

maria.ka.andersson@ regionostergotland.se

1 Division of Infectious Diseases, Department of Clinical and Experimental Medicine, Faculty of Medicine and Health Sciences, Linköping University, Linköping, Sweden

2 Occupational and Environmental Medicine, Department of Clinical and Experimental Medicine, Faculty of Medicine and Health Sciences, Linköping University, Linköping, Sweden

3 Forum Östergötland, Faculty of Medicine and Health Sciences, Linköping University, Linköping, Sweden

4 Department of Urology and Department of Clinical and Experimental Medicine, Linköping University, Linköping, Sweden

5 Division of Cardiothoracic Anesthesia and Intensive Care, Department of Medicine and Health Science, Faculty of Medicine and Health Sciences, Linköping University, Linköping, Sweden

\section{Introduction}

Sepsis and septic shock are common causes of mortality and morbidity in Sweden and globally. The reported annual incidence of sepsis varies depending on the method used to identify cases, but estimates of sepsis and septic shock rates lie around 500/100,000/year and 30-50/100,000/year, respectively [1-7].

Early recognition with resuscitation [8] and appropriate antibiotic treatment is known to be crucial for survival. Delayed appropriate antibiotic treatment has been shown to be an independent risk factor for mortality both in severe sepsis and septic shock [9-15], a fact that was confirmed in a recent systematic review of the literature [16].

Time to first antibiotic has been well studied, but administration of subsequent doses has received less attention. However, Leisman et al. [17] found that a major delay (> $25 \%$ ) of the second dose was associated with increased 
hospital mortality. This is supported by pharmacokinetic/ pharmacodynamic (PK/PD) studies showing that optimising antibiotic administration may increase survival [18-20].

The Surviving Sepsis Campaign Guidelines recommends broad-spectrum antibiotics within $1 \mathrm{~h}$ after detection as a part of the treatment bundle [21]. We are unaware of any treatment bundle including subsequent dosing. Consequently, less attention is paid to improving this in sepsis quality initiatives.

Our hypothesis was that early appropriate antibiotic treatment, i.e. first and second antibiotic dose at the right time, leads to improved outcome.

The aim of this study was to investigate the effect of early treatment on 28-day mortality, with focus on appropriate administration of first and second doses of antibiotic(s), in patients with community-onset severe sepsis and septic shock.

\section{Materials and methods}

\section{Study design and settings}

A retrospective, observational cohort study was conducted at Linköping University Hospital, Sweden, from September 30, 2012, until September 30, 2013. All patients aged 18 years or older with the International Classification of Disease ICD10SE diagnosis A 40 (bacteraemia caused by Streptococci), A 41 (other bacteraemia), R65.1 (severe sepsis) or R57.2 (septic shock) [22] at discharge, cared for in the intensive care unit (ICU) and the Departments of Infectious Disease and Acute Internal Medicine including the medical high dependency unit, were identified. We included only patients admitted to these departments since they are specialised in caring for patients with community-onset severe sepsis or septic shock. Of these, patients who met the criteria of community-onset (defined as no hospitalisation within 30 days prior to admission) severe sepsis or septic shock within $24 \mathrm{~h}$ after arrival at the emergency department (ED) were included. Flowchart for inclusion and exclusion is shown in Fig. 1.

The study was performed in a tertiary care university hospital which serves a primary population of 172,000 , with no other ED in the catchment area. Patients transferred from another hospital were excluded.

Patients were only included once, i.e. the primary admission with community-onset severe sepsis or septic shock within the study period.

\section{Data collection}

All data and records were reviewed by the first author. Any ambiguities concerning application of definitions or clinical treatments were resolved within the study group consisting of senior infectious disease consultants and an ICU physician. The primary endpoint was 28-day mortality. Secondary outcomes were achievement of "early appropriate antibiotic treatment" and treatment goals at 1 and $6 \mathrm{~h}$ according to the Surviving Sepsis Campaign (SSC) at the time, and the Swedish Society of Infectious Diseases' treatment goals [23, 24].

The following baseline characteristics were registered: gender, age, weight, renal function $\left(\mathrm{eGFR}<30 \mathrm{ml} / \mathrm{min} \times \mathrm{m}^{2}\right)$ and previously diagnosed comorbidity. Severity of disease was assessed by Medical Emergency Triage and Treatment System Adult (METTS) [25, 26], APACHE II score [27] and SOFA score [28]. Indicators of appropriate early treatment (resuscitation, antibiotic treatment and fulfilment of early treatment goals (see definition below)), limitation of level of care, ICU admission, length of stay, indicators of organ dysfunction, focus of infection, aetiology and 28-day mortality were also registered.

APACHE II and SOFA scores were calculated from the time of arrival at the emergency department. Laboratory parameters and vital signs were followed over the first $48 \mathrm{~h}$ (exception made for CRP which was followed until $72 \mathrm{~h}$ after admission).

Antibiotic administration data recorded were as follows: agent(s), dose, time of administration of first and second doses of appropriate antibiotic and recommended dose interval(s).

\section{Definitions of appropriate and early antibiotic treatment}

1. Appropriate antibiotic treatment: The following major criteria had to be fulfilled:

(a) Treatment with antibiotic agent(s), including dose and dose interval according to the national treatment guidelines [24]

(b) Susceptibility of the pathogen(s) isolated to the agent(s) used (if the patient had a culture-negative sepsis only " $\mathrm{a}$ " had to be fulfilled) [11]

\section{Early appropriate antibiotic treatment}

To fulfil the definition of early appropriate antibiotic treatment, the 1st dose fulfilling the major criteria had to be administered within $1 \mathrm{~h}$, and the 2 nd dose fulfilling the major criteria given with less than $25 \%$ delay based on the recommended dose interval in the national treatment guidelines.

In cases of uncertainty, evaluation of the appropriateness of antibiotic treatment was discussed in the study group consisting of senior infectious disease consultants and an ICU physician.

The timing of the 2nd dose of an appropriate antibiotic with renal elimination took into consideration the increased dose interval due to reduced renal excretion. When more than one adequate antibiotic was given, the longest recommended dose interval was applied [17]. The ratio for time interval between 
Fig. 1 Flowchart for inclusion and exclusion

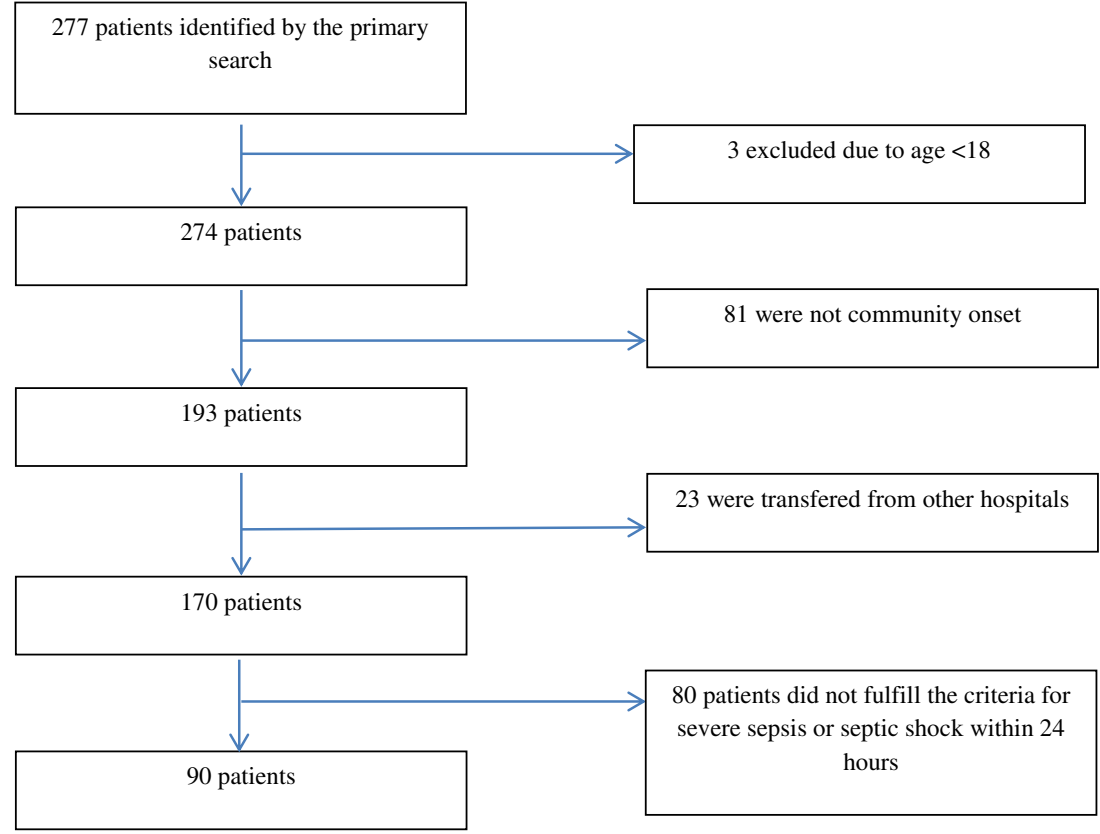

the first and second doses was calculated as the actual time divided by the recommended time interval. For patients not receiving effective antibiotic therapy within $24 \mathrm{~h}$, time to second dose and 1 st-to-2nd dose interval ratio was not calculated.

\section{Treatment goals and resuscitation}

Treatment goals for the first hour were systolic blood pressure $>90 \mathrm{mmHg}$ and oxygen saturation $>93 \%$. Goals within $6 \mathrm{~h}$ were urinary production $>0.5 \mathrm{ml} / \mathrm{kg} / \mathrm{h}$, fall in lactate level and mean arterial pressure (MAP) $\geq 65 \mathrm{mmHg}[23,24]$.

Fluid resuscitation was recorded as type and amount of fluid given in the time intervals $0-2 \mathrm{~h}, 2-6 \mathrm{~h}$ and $6-24 \mathrm{~h}$. Since the composition of the fluid therapy (crystalloids, colloids and blood products) varied between patients, the predicted intravascular volume expansion was calculated in order to compare the effect of fluids administered. Taking into account their extravascular distribution, crystalloid volume was multiplied by a factor of 0.25 , albumin solutions $40-50 \mathrm{mg} / \mathrm{ml}$ by a factor of 0.5 , albumin solutions $200 \mathrm{mg} / \mathrm{ml}$ by a factor of 1.5 , plasma by a factor of 0.5 and blood transfusion by a factor of 1. Glucose infusion given slowly for calorific purposes was not included in the fluid calculations.

\section{Limitation of level of care}

For some of the patients included, the decision was made to limit the level of care. As such a decision influences both treatment given and mortality, this was a potential confounding factor. Limitation of level of care set within the first $24 \mathrm{~h}$ was registered as withholding: (a) ICU, (b) ventilator support, (c) dialysis, (d) cardiopulmonary resuscitation (CPR) and (e) withdrawal of all active treatment.

\section{Definitions of sepsis, high-risk patient, infection and focus of infection}

This study was performed prior to the introduction of the new sepsis definitions, Sepsis-3 [29], and hence, definitions according to the SSC criteria of 2012 were used [23].

Sepsis: The systemic inflammatory response (SIRS) to infection [30].

Severe sepsis: Sepsis with hypotension (systolic blood pressure $(\mathrm{SBP})<90 \mathrm{mmHg}$ or $\mathrm{MAP}<70 \mathrm{mmHg}$ ), hypoperfusion (P-lactate $>1 \mathrm{mmol} / 1$ above reference $(3.4 \mathrm{mmol} / \mathrm{l})$, base excess $(\mathrm{BE}) \leq-5 \mathrm{mmol} / \mathrm{l})$ or one or more of the following organ dysfunctions: renal (oliguria $<0.5 \mathrm{ml} / \mathrm{kg} / \mathrm{h} \geq 2 \mathrm{~h}$ despite resuscitation, or serum creatinine elevated $>45 \mu \mathrm{mol}$ above the patient's former value if known), respiratory $\left(\mathrm{PaO}_{2} /\right.$ $\mathrm{FiO}_{2}<33 \mathrm{kPa}$ without or $<27 \mathrm{kPa}$ with pneumonia), coagulation defect (platelet count $<100 \times 10^{9} / 1$, PT-INR $>1.5$ or APTT $>60 \mathrm{~s}$ ), CNS (altered mental status) or hepatic (S-bilirubin $>45 \mu \mathrm{mol} / \mathrm{l})$.

Septic shock: Severe sepsis with sepsis-induced hypotension unresponsive to fluid resuscitation, together with hypoperfusion or organ dysfunction $[3,23,30]$.

High-risk patient: Patients with red triage level according to METTS on arrival at the ED, or patients with septic shock on admission or shock within $24 \mathrm{~h}$ after arrival at the ED. Red triage level according to METTS is defined as a lifethreatening condition requiring immediate medical attention by a physician. This identifies a more severely ill cohort of severe sepsis patients where more prompt treatment on the ED 
might have prevented progress to shock. Thus, the combination resulting in the high-risk patient definition better identifies the population of severely ill septic patients.

Infection sites: The definitions suggested by the International Sepsis Forum Consensus Conference on Definitions of Infections in the Intensive Care Unit [31] were used, with minor changes.

Bloodstream infection (BSI): Isolation of bacteria or fungi from at least one blood culture. Microorganisms typically belonging to skin flora were considered a contamination.

Pneumonia: Symptoms and radiology indicating pneumonia.

Urosepsis: Positive culture from blood or two of the following: fever $>38^{\circ} \mathrm{C}$, symptoms of UTI, relevant pathogens in the urine or radiographic evidence.

Skin and soft tissue infection: Erysipelas, cellulitis, fasciitis or wound infection.

Intra-abdominal infection: Symptoms and radiologic evidence, or findings during surgery of intra-abdominal infection. In case of surgery, positive blood cultures were required prior to surgery.

Infective endocarditis: Definite infective endocarditis according to the modified Duke criteria [31,32].

Microbiological aetiology: Detection of relevant pathogens in cultures, by antigen testing or PCR technique.

Community-onset: No hospitalisation within 30 days prior to admission.

\section{Statistical analyses}

The primary outcome variable was 28 -day mortality. The whole study group was analysed as such, and a subgroup analysis of high-risk patients was made. The statistical programs STATA v15 and SPSS version 24 were used for the analyses. We compared normally distributed quantitative variables with the $t$ test and categorical variables using the $\mathrm{chi}^{2}$ test or Fisher exact test. Mann-Whitney $U$ test was used for fluid volumes. Double-sided $P$ values were used. A $P$ value $<$ 0.05 was considered statistically significant. Missing data were treated by pairwise deletion, and there was no imputation. A multivariable analysis was performed with logistic regression including the univariate parameters correlating to 28-day mortality followed by stepwise removal of parameters.

\section{Results}

\section{Characteristics of the study population}

There were 90 patients enrolled in the study, mean age was 73 years and $51 \%$ were female. Overall 28 -day mortality was $26.7 \%$. Baseline characteristics are shown in Table 1. Sixtythree patients had severe sepsis without shock and 27 patients developed shock within $24 \mathrm{~h}$, with mortality rates of $17.5 \%$ and $48.2 \%$, respectively. There were no differences in age or gender regarding the risk for developing septic shock (data not shown).

Significantly increased mortality in the total study population was associated with higher age, presence of shock or being a high-risk patient (see below), higher maximum lactate level, respiratory and renal dysfunction due to the infection and number of dysfunctional organs.

A subgroup analysis was made on high-risk patients (patient with red triage level according to METTS in the ED or shock within $24 \mathrm{~h}$ after arrival at the ED) (Table 1).

Clinical interventions and treatment evaluations are shown in Table 2. Limitation of level of care and failure to achieve haemodynamic stability within $6 \mathrm{~h}$ (MAP $\geq 65 \mathrm{mmHg}$ within $6 \mathrm{~h})$ were associated with increased mortality. More extensive fluid administration late in the course (6-24 h) was also related to higher mortality. Twenty-four patients were treated for sepsis on the ICU at some time during their hospital stay. The 28-day mortality rate was $38 \%$ among ICU-treated patients $(9 / 24)$ and $23 \%$ (15/66) among patients treated on the general ward or intermediate care unit. This difference, however, was not significant.

During the first $24 \mathrm{~h}, 26 \%$ (23/90) of the patients had their level of care limited, and their mortality rate was $56.5 \%$. Typical for this group were increased age, presence of congestive heart failure, higher APACHE II score and an increased number of failing organs due to infection. These patients received more fluid between 6 and $24 \mathrm{~h}$, but there were no other significant differences regarding clinical interventions. Data on this are presented in the supplementary files. When excluding patients with care limitation, mortality in the study population was $16 \%$ (11/67) and in the high-risk group 17\% (5/30).

\section{Focus of infection, microbiological diagnosis}

Urinary tract infection (UTI) followed by pneumonia, skin and soft tissue infection (SSI) and infection of unknown origin were the four most common foci (Table 3). Mortality was highest among patients with unknown focus (7/12). Blood cultures were obtained from all but two patients, but only $50 \%$ were positive. A culture-confirmed focus of infection was found in 73\% (66/90) of patients, and 79\% (71/90) had a microbiological diagnosis (based on cultures, antigen testing or PCR technique) (Table 4).

The most common pathogen was Escherichia coli (E. coli) (23\% of the patients), followed by Streptococcus pyogenes (10\%). The frequency of Staphylococcus aureus (S. aureus) was only $7 \%(6 / 90)$, with a mortality of $67 \%$, although based on very few cases. Two patients were treated for sepsis caused by extended spectrum beta lactamase-producing Enterobacteriaceae $\left(\mathrm{ESBL}_{\mathrm{A}}\right)$ and one patient for sepsis due to Streptococcus pneumoniae with reduced susceptibility to 


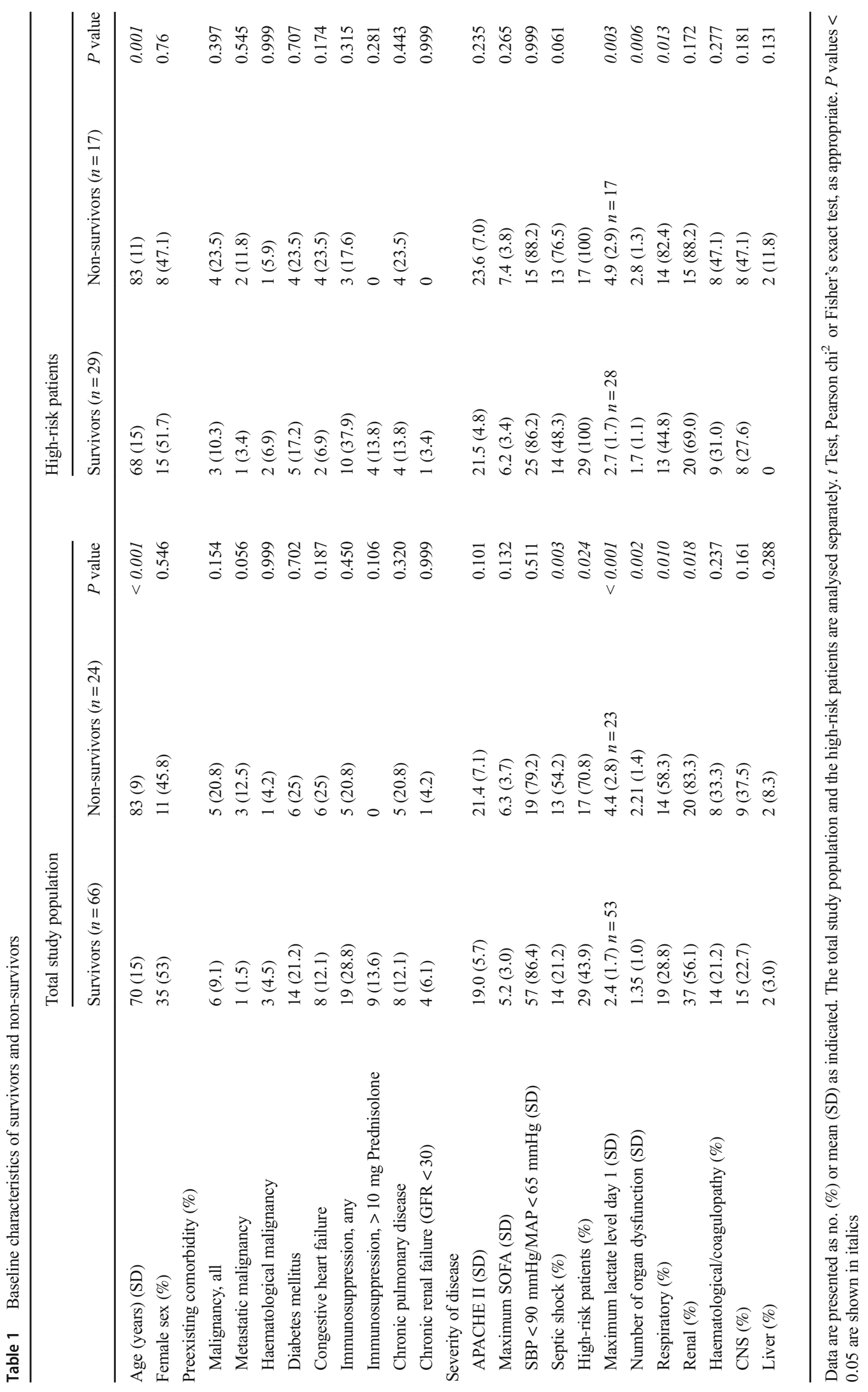




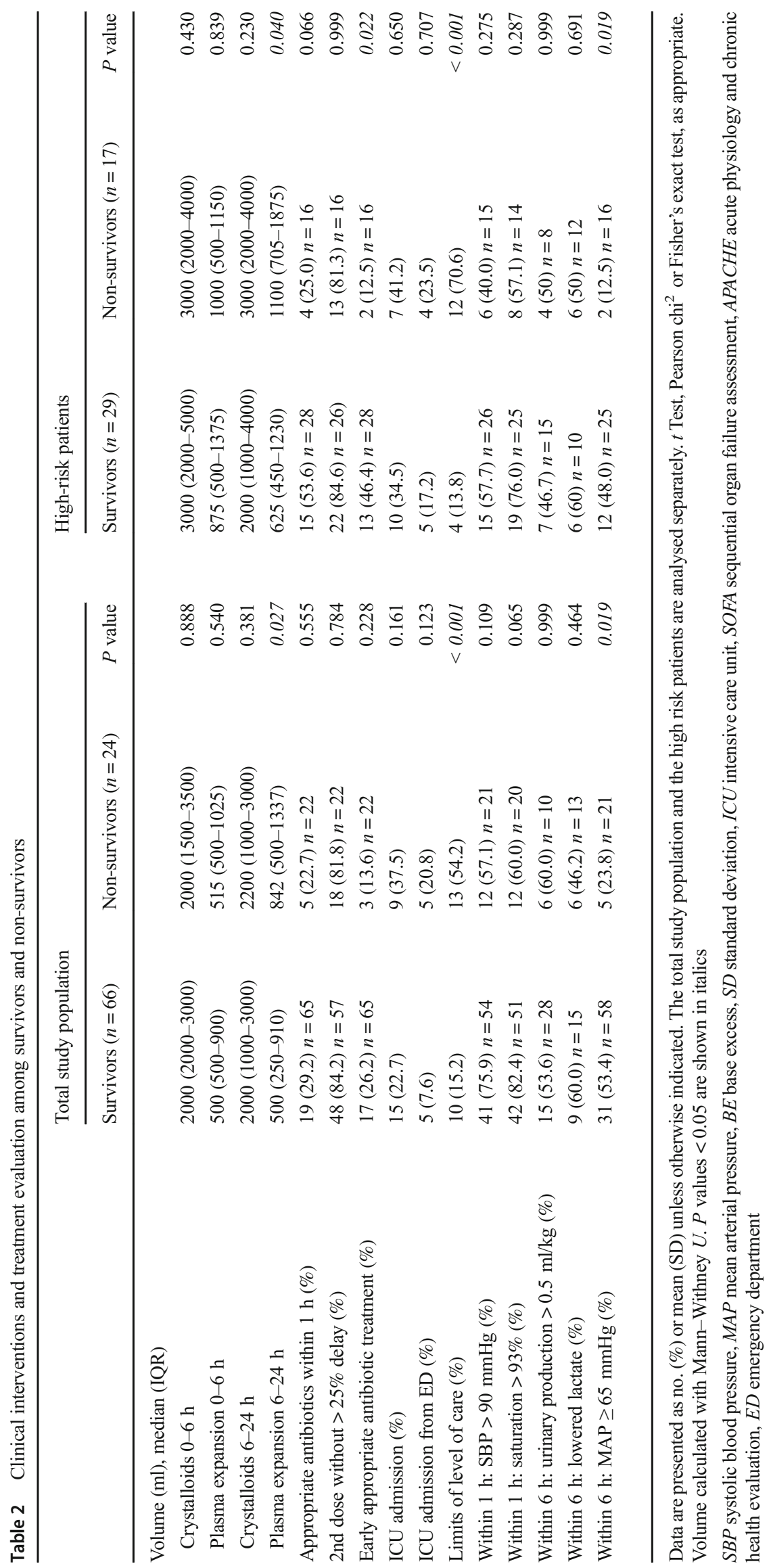


Table 3 Focus of infection among survivors and non-survivors

\begin{tabular}{|c|c|c|c|c|c|}
\hline Source of infection & Frequency $(\%)$ & Survivors $(n)$ & Non-survivors $(n)$ & Mortality (\%) & $P$ value \\
\hline Urinary $(n=33)$ & 36.7 & 26 & 7 & 21.2 & $0.37^{1}$ \\
\hline Pulmonary $(n=23)$ & 25.6 & 19 & 4 & 17.3 & $0.24^{1}$ \\
\hline Skin and soft tissue $(n=15)$ & 16.7 & 12 & 3 & 25.0 & $0.52^{1}$ \\
\hline Intra-abdominal $(n=4)$ & 4.4 & 2 & 2 & 50.0 & $0.29^{2}$ \\
\hline Endocarditis $(n=2)$ & 2.2 & 1 & 1 & 50.0 & $0.46^{2}$ \\
\hline Others $(n=1)$ & 1.1 & 1 & 0 & 0 & $0.99^{2}$ \\
\hline Unknown $(n=12)$ & 13.3 & 5 & 7 & 58.3 & $0.01^{1}$ \\
\hline
\end{tabular}

Data are presented no. $(\%) .{ }^{1}$ Pearson chi $^{2}$ or ${ }^{2}$ Fisher's exact test. $P$ values $<0.05$ are shown in italics

penicillin. There were no cases of methicillin-resistant Staphylococcus aureus (MRSA) or vancomycin-resistant Enterococci (VRE) (Table 5).

\section{High-risk patients}

Mortality was $37 \%$ among the 46 high-risk patients. Higher age, maximum lactate level, number of failing organs and respiratory dysfunction due to infection were associated with increased mortality (Table 1).

Early appropriate antibiotic treatment and haemodynamic stability (MAP $\geq 65 \mathrm{mmHg}$ ) within $6 \mathrm{~h}$ were associated with decreased mortality. Non-survivors received more intravenous fluid in the latter part of the course of the disease (6-24 h). Limitation of level of care was more common among nonsurvivors (Table 2).

\section{Antibiotic treatment}

Data on antibiotic treatment are shown in Table 2. Twentyfour out of 87 patients received the first dose of appropriate antibiotic within $1 \mathrm{~h}$ (data regarding three patients were missing). In all, 23\% (20/87) of the patients received early appropriate antibiotic treatment including 1 st and 2 nd doses. In the subgroup of high-risk patients, $34 \%$ (15/44) received early appropriate antibiotic treatment.

Of the 67 patients receiving inappropriate early antibiotic treatment, the main failure was delay of the first dose in 63 cases. Major delay of the second dose was found in 13/79 patients, and nine patients had a delay in the administration of both first and second doses. The majority received cefotaxime $(60 \%)$ or piperacillin-tazobactam (16\%), alone or in combination with another antibiotic. Carbapenems were used in $7 \%$. No patient received vancomycin. Of the 71 patients with known aetiology, six patients received initial treatment with an antibiotic with inappropriate spectrum.

Among the high-risk patients, administration of early appropriate antibiotic treatment correlated to a lower 28-day mortality (Table 2).

\section{Risk factors for inappropriate antibiotic administration}

Risk factors for delay of early appropriate antibiotic treatment (shown in Table 6) were lower triage level, lower disease severity (APACHE II and SOFA score) on arrival and administration of the first dose after transfer from the ED. Patients on immunosuppression received timely antibiotic treatment more frequently.

\section{Achievement of treatment goals}

"Achievement of treatment goal" was a secondary outcome. For all patients, an oxygen saturation $>93 \%$ within $1 \mathrm{~h}$ and an established MAP $\geq 65 \mathrm{mmHg}$ within $6 \mathrm{~h}$ correlated with survival. Other treatment goals did not show any correlation with 28-day mortality, but data were missing in many cases (e.g. in $52 / 90$ cases data were missing regarding urinary production within $6 \mathrm{~h}$ and in 62/90 cases regarding lactate level within $6 \mathrm{~h})$.

Table 4 Microbiological characteristics of survivors and non-survivors

\begin{tabular}{llll}
\hline & Survivors $(n=66)$ & Non-survivors $(n=24)$ & $P$ value \\
\hline Positive blood culture & $30(45.5)$ & $15(62.5)$ & 0.161 \\
Any relevant culture & $48(72.7)$ & $18(75)$ & 0.829 \\
Positive diagnostics & $52(78.8)$ & $19(79.2)$ & 0.969 \\
\hline
\end{tabular}

Data are presented as no. (\%) Pearson $\mathrm{chi}^{2}$ test. A $P$ value $<0.05$ was considered statistically significant. There were no signicant differences between the groups 
Table 5 Microbiological characteristics of survivors and non-survivors

\begin{tabular}{|c|c|c|c|c|c|}
\hline Microbiological cause & Frequency $(\%)$ & Survivors $(n=66)$ & Non-survivors $(n=24)$ & Mortality $\%$ & $P$ value \\
\hline \multicolumn{6}{|l|}{ Gram-negative bacteria } \\
\hline Escherichia coli & 23 & 15 & 6 & 29 & $0.82^{1}$ \\
\hline Klebsiella spp. & 6 & 3 & 2 & 40. & $0.61^{2}$ \\
\hline Other Enterobactericeae & 7 & 4 & 0 & 0 & $0.57^{2}$ \\
\hline Pseudomonas aeruginosa & 2 & 2 & 0 & 0 & $0.99^{2}$ \\
\hline Neisseria meningitidis & 1 & 1 & 0 & 0 & $0.99^{2}$ \\
\hline \multicolumn{6}{|l|}{ Gram-positive bacteria } \\
\hline Streptococcus pyogenes & 10 & 7 & 2 & 22 & $0.99^{2}$ \\
\hline Streptococcus pneumoniae & 8 & 6 & 1 & 17 & $0.67^{2}$ \\
\hline Other Streptococcus spp. & 4 & 3 & 1 & 25 & $0.99^{2}$ \\
\hline Enterococcus.faecalis & 3 & 3 & 0 & 0 & $0.56^{2}$ \\
\hline Staphylococcus aureus & 7 & 2 & 4 & 67 & $0.04^{2}$ \\
\hline Clostridium difficile & 1 & 1 & 0 & 0 & 0.54 \\
\hline Multiple pathogens & 9 & 5 & 3 & 38 & 0.47 \\
\hline No positive diagnostics & 21 & 14 & 5 & 26 & 0.97 \\
\hline
\end{tabular}

Causative microbiological agent was based on cultures, antigen test and PCR methods. Data are presented as no. $(\%) .{ }^{1}$ Pearson chi ${ }^{2},{ }^{2}$ Fisher's exact test. $P$ values $<0.05$ are shown in italics

\section{Multivariable analysis}

A multivariable analysis was performed on the high-risk patients (Table 7). At first, we included variables with a univariate correlation to 28-day mortality (age, maximum lactate level, number of dysfunctional organs, plasma expansion at 6-24 h, early appropriate antibiotic treatment, limit of level of care and MAP $\geq 65 \mathrm{mmHg}$ within $6 \mathrm{~h}$ ) within a logistic regression. Stepwise removal of the parameter with the highest $P$ value rendered a three-variable model with the parameters age, early appropriate antibiotic treatment and limit of level of care giving the best fit.

The 28 -day mortality was $46.4 \%$ among the high-risk patients who did not receive early appropriate antibiotic treatment compared with $12.5 \%$ among those who did (Table 2). This illustrates a more than threefold higher mortality rate among the high-risk patients who did not receive early appropriate antibiotic treatment (Table 2). In the multivariable analysis, inappropriate antibiotic therapy was found to be an independent predictor of mortality with an odds ratio for mortality of 10.4 in the high-risk group (Table 7).

\section{Discussion}

In this retrospective cohort of adult patients with severe sepsis and septic shock, we found in the univariate analysis a greater than threefold increase in mortality rate among high-risk patients not receiving early appropriate antibiotic treatment. In the multivariable analysis, inappropriate early antibiotic therapy was found to be an independent predictor of mortality with an odds ratio for mortality of 10.4 in the high-risk group.

The importance of timing and appropriateness of the first dose of antibiotics has been shown in previous studies, especially in septic shock [9-15, 33]. Leisman et al. studied the importance of timely administration of the 2 nd dose and showed that major delay in the 2 nd dose was associated with higher mortality [17]. Therapeutic antibiotic concentrations in blood and at the target site must be achieved and maintained as quickly as possible in order to reduce bacterial load [20]. Thus, adequate dose and dose intervals of antibiotics are crucial for improving prognosis. In retrospective material, timing of both first and second doses may be a marker of suboptimal initial treatment and improper pharmacokinetic adaptation. In the setting of this study, antibiotic treatment was usually initiated in the ED, followed by a transfer to the ward or ICU, making delay in the second dose a risk due to logistic reasons.

The importance of adequate dosing on survival is supported by PK/PD studies [18-20] and is even more important in the treatment of critically ill patients, due to more complicated pharmacokinetics [20,34]. Change in distribution volume influences the plasma and tissue concentrations of water-soluble antibiotics, and glomerular filtration rate may be altered $[18$, 35] Tissue perfusion may be decreased, making it more difficult for the antibiotic to reach its target [36]. Antibiotic blood concentrations in the critically ill are often subtherapeutic [19, 34-36], and for that reason, therapeutic drug monitoring (TDM) is becoming more widespread [34]. This stresses the importance of adequate dosage, not only the first dose but also subsequent doses of the antibiotics, in order to achieve appropriate antibiotic exposure. 


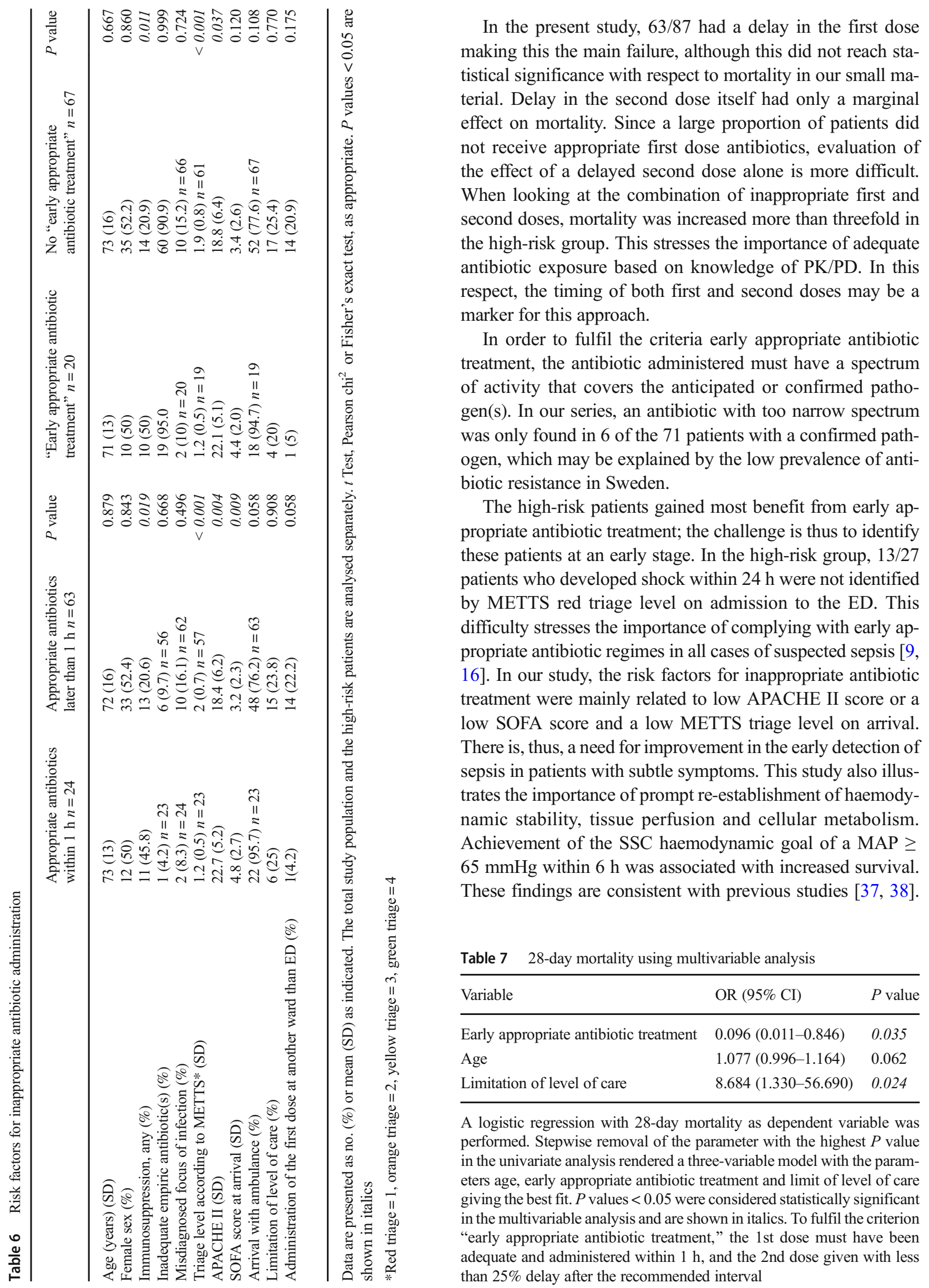


Fluid therapy only differed between survivors and nonsurvivors in the latter part of the resuscitation period (6$24 \mathrm{~h}$ ), where the non-survivors received more volume expansion. This probably reflects therapeutic efforts to restore haemodynamic stability in patients with prolonged circulatory failure not responding to initial fluid therapy, i.e. those with a poor prognosis. Maximum lactate level also correlated with mortality, illustrating the impact of disease severity, also seen in previous studies [39, 40].

The distribution of aetiologic pathogens and foci might have been influenced by the restricted inclusion material comprising patients from medical wards and the ICU only. E. coli was the most prevalent pathogen, which is in agreement with a previous study including all patients with bacteraemia in the same hospital [41]. S. aureus, on the other hand, was found in only six patients (7\%). This incidence is lower than seen in many other studies (12-18\%) based on positive blood cultures $[2,41,42]$. Our findings are supported by the National Register of Community-Acquired Sepsis of the Swedish Infectious Diseases Physicians Society, where $S$. aureus was the causing pathogen in $8-10 \%$ of cases during the same period of time [24]. The high mortality in the subgroup of $S$. aureus infections in our material (4/6) is deemed not to be representative but rather an effect of the small sample size. The prevalence of antibiotic resistance in Sweden is low, and our finding of a low level of resistant pathogens in this study is in line with Swedish resistance surveillance data [43].

Early antibiotic treatment was the main focus in this study, but data also revealed other important risk factors for mortality. Age, markers of severity of disease (maximum lactate level and number of dysfunctioning organs) and treatment (limited level of care, haemodynamic stabilisation, administration of fluids and antibiotics) were all correlated to mortality in the univariate analysis. All are known risk factors relating to outcome [39, 44-47]. The impact of treatment, including limit of level of care, is determined by the clinical management of the individual patient and thereby possible to modify in order to improve patient outcome. In the multivariable analysis, best fit was found for the model incorporating age, limited level of care and early appropriate antibiotic treatment as independent factors related to mortality. Patients with treatment limitation had, as might be expected, a higher mortality rate $[46,47]$. This is an important factor to consider. Limitation of the level of care must be considered carefully since this may result in substandard care and increased morbidity and mortality if not applied correctly - fulfilment of the prophesy. In our study, those receiving limited care received more fluids in the latter part of the clinical period (6-24 h), which may have been the result of not being treated with inotropes. The mortality in the group that received limited care in our study was high, but we have no way of assessing the correctness of the restrictions applied.
Whatever, care limitation must be thoroughly discussed and evaluated at the local level.

Even though our theoretical knowledge of sepsis treatment has improved over the last decade, there is much room for improvement in the practical management of the septic patient. Only $23 \%$ of patients with sepsis received early appropriate antibiotic treatment, and only $34 \%$ among obviously high-risk patients. This indicates shortcomings in the management of sepsis patients. Failure to achieve haemodynamic stability, seen as the lower number of patients with MAP > $65 \mathrm{mmHg}$ at $6 \mathrm{~h}$, also illustrates this point. Less than one in three patients with sepsis were treated on the ICU, even though more than half of the patients, in which treatment goals could be evaluated, were still not haemodynamically stable after $6 \mathrm{~h}$.

This study has several limitations. It is a small, retrospective, single-centre study, making the results difficult to generalise. The distribution of aetiologic pathogens and infectious foci might have been influenced by the restricted inclusion material from medical wards and the ICU only. Some of the treatment goals were difficult to evaluate due to missing data.

Identification of septic patients using ICD-10 codes is also problematic and can lead to loss of cases as many patients lack specific sepsis codes at discharge [7]. Exclusion of patients who had been hospitalised within 30 days before admission also contributed to case loss.

This study also has strengths. The addition of sepsis criteria to the ICD-10 codes for inclusion resulted in a more welldefined study group. This is supported by Rhee et al., who found that sepsis based on clinical information increased the confidence in sepsis estimates, compared to identification by ICD-10 alone [5]. The use of both septic shock and METTS criteria resulted in a more precise identification of high-risk patients. Recruiting patients from medical wards and not just from the ICU better reflects the sepsis population in the Swedish healthcare system.

In conclusion, we found suboptimal initial management of septic patients at our hospital, with a more than threefold increase in mortality among high-risk patients not receiving early appropriate antibiotic treatment. Even though the importance of early antibiotic treatment has been established for a long time, adherence to this principle was very low. There is much room left for improvement in the early identification and appropriate antibiotic treatment of sepsis patients.

\section{Compliance with ethical standards}

The study was approved by the Ethics Review Board of Linköping University, Sweden (2013/466-31) and was performed in accordance with the Helsinki Declaration. The study was funded by the County of Östergötland. 
Conflict of interest The authors declare that they have no conflict of interest.

Open Access This article is distributed under the terms of the Creative Commons Attribution 4.0 International License (http:// creativecommons.org/licenses/by/4.0/), which permits unrestricted use, distribution, and reproduction in any medium, provided you give appropriate credit to the original author(s) and the source, provide a link to the Creative Commons license, and indicate if changes were made.

\section{References}

1. Mellhammar L, Wullt S, Lindberg A, Lanbeck P, Christensson B, Linder A (2016) Sepsis incidence: a population-based study. Open Forum Infect Dis 3(4):ofw207

2. Henriksen DP, Laursen CB, Jensen TG, Hallas J, Pedersen C, Lassen AT (2015) Incidence rate of community-acquired sepsis among hospitalized acute medical patients-a population-based survey. Crit Care Med 43(1):13-21

3. van Gestel A, Bakker J, Veraart CP, van Hout BA (2004) Prevalence and incidence of severe sepsis in Dutch intensive care units. Crit Care 8(4):R153-R162

4. Kaukonen KM, Bailey M, Suzuki S, Pilcher D, Bellomo R (2014) Mortality related to severe sepsis and septic shock among critically ill patients in Australia and New Zealand, 2000-2012. JAMA 311(13):1308-1316

5. Rhee C, Dantes R, Epstein L, Murphy DJ, Seymour CW, Iwashyna TJ, Kadri SS, Angus DC, Danner RL, Fiore AE, Jernigan JA, Martin GS, Septimus E, Warren DK, Karcz A, Chan C, Menchaca JT, Wang R, Gruber S, Klompas M, Program CDCPE (2017) Incidence and trends of sepsis in US hospitals using clinical vs claims data, 2009-2014. JAMA 318(13):1241-1249

6. Linder A, Guh D, Boyd JH, Walley KR, Anis AH, Russell JA (2014) Long-term (10-year) mortality of younger previously healthy patients with severe sepsis/septic shock is worse than that of patients with nonseptic critical illness and of the general population. Crit Care Med 42(10):2211-2218

7. Wilhelms SB, Walther SM, Huss F, Sjoberg F (2017) Severe sepsis in the ICU is often missing in hospital discharge codes. Acta Anaesthesiol Scand 61(2):186-193

8. Rivers E, Nguyen B, Havstad S, Ressler J, Muzzin A, Knoblich B, Peterson E, Tomlanovich M, Early Goal-Directed Therapy Collaborative G (2001) Early goal-directed therapy in the treatment of severe sepsis and septic shock. N Engl J Med 345(19):13681377

9. Ferrer R, Martin-Loeches I, Phillips G, Osborn TM, Townsend S, Dellinger RP, Artigas A, Schorr C, Levy MM (2014) Empiric antibiotic treatment reduces mortality in severe sepsis and septic shock from the first hour: results from a guideline-based performance improvement program. Crit Care Med 42(8):1749-1755

10. Kumar A, Haery C, Paladugu B, Kumar A, Symeoneides S, Taiberg L, Osman J, Trenholme G, Opal SM, Goldfarb R, Parrillo JE (2006) The duration of hypotension before the initiation of antibiotic treatment is a critical determinant of survival in a murine model of Escherichia coli septic shock: association with serum lactate and inflammatory cytokine levels. J Infect Dis 193(2):251-258

11. Kumar A, Ellis P, Arabi Y, Roberts D, Light B, Parrillo JE, Dodek P, Wood G, Kumar A, Simon D, Peters C, Ahsan M, Chateau D, Cooperative Antimicrobial Therapy of Septic Shock Database Research G (2009) Initiation of inappropriate antimicrobial therapy results in a fivefold reduction of survival in human septic shock. Chest 136(5): 1237-1248

12. Lee CC, Lee CH, Chuang MC, Hong MY, Hsu HC, Ko WC (2012) Impact of inappropriate empirical antibiotic therapy on outcome of bacteremic adults visiting the ED. Am J Emerg Med 30(8):14471456

13. Nygard ST, Langeland N, Flaatten HK, Fanebust R, Haugen O, Skrede S (2014) Aetiology, antimicrobial therapy and outcome of patients with community acquired severe sepsis: a prospective study in a Norwegian university hospital. BMC Infect Dis 14:121

14. Puskarich MA, Trzeciak S, Shapiro NI, Arnold RC, Horton JM, Studnek JR, Kline JA, Jones AE, Emergency Medicine Shock Research N (2011) Association between timing of antibiotic administration and mortality from septic shock in patients treated with a quantitative resuscitation protocol. Crit Care Med 39(9):2066-2071

15. Gaieski DF, Mikkelsen ME, Band RA, Pines JM, Massone R, Furia FF, Shofer FS, Goyal M (2010) Impact of time to antibiotics on survival in patients with severe sepsis or septic shock in whom early goal-directed therapy was initiated in the emergency department. Crit Care Med 38(4):1045-1053

16. Sherwin R, Winters ME, Vilke GM, Wardi G (2017) Does early and appropriate antibiotic administration improve mortality in emergency department patients with severe sepsis or septic shock? J Emerg Med 53(4):588-595

17. Leisman D, Huang V, Zhou Q, Gribben J, Bianculli A, Bernshteyn M, Ward MF, Schneider SM (2017) Delayed second dose antibiotics for patients admitted from the emergency department with sepsis: prevalence, risk factors, and outcomes. Crit Care Med 45(6):956-965

18. Blot SI, Pea F, Lipman J (2014) The effect of pathophysiology on pharmacokinetics in the critically ill patient - concepts appraised by the example of antimicrobial agents. Adv Drug Deliv Rev 77:3-11

19. Roberts JA, Paul SK, Akova M, Bassetti M, De Waele JJ, Dimopoulos G, Kaukonen KM, Koulenti D, Martin C, Montravers P, Rello J, Rhodes A, Starr T, Wallis SC, Lipman J, Study D (2014) DALI: defining antibiotic levels in intensive care unit patients: are current beta-lactam antibiotic doses sufficient for critically ill patients? Clin Infect Dis 58(8):1072-1083

20. Kumar A (2014) An alternate pathophysiologic paradigm of sepsis and septic shock: implications for optimizing antimicrobial therapy. Virulence 5(1):80-97

21. Rhodes A, Evans LE, Alhazzani W et al (2017) Surviving sepsis campaign: international guidelines for management of sepsis and septic shock: 2016. Intensive Care Med 43(3):304-377

22. Islas-Munoz B, Volkow-Fernandez P, Ibanes-Gutierrez C, Villamar-Ramirez A, Vilar-Compte D, Cornejo-Juarez P (2018) Bloodstream infections in cancer patients. Risk factors associated with mortality. Int J Infect Dis 71:59-64

23. Dellinger RP, Levy MM, Rhodes A, Annane D, Gerlach H, Opal SM, Sevransky JE, Sprung CL, Douglas IS, Jaeschke R, Osborn TM, Nunnally ME, Townsend SR, Reinhart K, Kleinpell RM, Angus DC, Deutschman CS, Machado FR, Rubenfeld GD, Webb S, Beale RJ, Vincent JL, Moreno R, Surviving Sepsis Campaign Guidelines Committee including The Pediatric S (2013) Surviving sepsis campaign: international guidelines for management of severe sepsis and septic shock, 2012. Intensive Care Med 39(2):165-228

24. Seddon MM, Bookstaver PB, Justo JA, Kohn J, Rac H, Haggard E, Mediwala KN, Dash S, Al-Hasan MN (2018) Role of early deescalation of antimicrobial therapy on risk of Clostridioides difficile infection following Enterobacteriaceae bloodstream infections. Clin Infect Dis

25. Widgren BR, Jourak M, Martinius A (2008) New accurate triage method. METTS-A yields basis for priority level decisions. Lakartidningen 105(4):201-204

26. Widgren BR, Jourak M (2011) Medical Emergency Triage and Treatment System (METTS): a new protocol in primary triage 
and secondary priority decision in emergency medicine. J Emerg Med 40(6):623-628

27. Knaus WA, Draper EA, Wagner DP, Zimmerman JE (1985) APACHE II: a severity of disease classification system. Crit Care Med 13(10):818-829

28. Vincent JL, Moreno R, Takala J, Willatts S, De Mendonca A, Bruining H, Reinhart CK, Suter PM, Thijs LG (1996) The SOFA (Sepsis-related Organ Failure Assessment) score to describe organ dysfunction/failure. On behalf of the Working Group on SepsisRelated Problems of the European Society of Intensive Care Medicine. Intensive Care Med 22(7):707-710

29. Singer M, Deutschman CS, Seymour CW, Shankar-Hari M, Annane D, Bauer M, Bellomo R, Bernard GR, Chiche JD, Coopersmith CM, Hotchkiss RS, Levy MM, Marshall JC, Martin GS, Opal SM, Rubenfeld GD, van der Poll T, Vincent JL, Angus DC (2016) The third international consensus definitions for sepsis and septic shock (Sepsis-3). JAMA 315(8):801-810

30. Bone RC, Balk RA, Cerra FB, Dellinger RP, Fein AM, Knaus WA, Schein RM, Sibbald WJ (1992) Definitions for sepsis and organ failure and guidelines for the use of innovative therapies in sepsis. The ACCP/SCCM Consensus Conference Committee. American College of Chest Physicians/Society of Critical Care Medicine. Chest 101(6):1644-1655

31. Calandra T, Cohen J, International Sepsis Forum Definition of Infection in the ICUCC (2005) The international sepsis forum consensus conference on definitions of infection in the intensive care unit. Crit Care Med 33(7):1538-1548

32. Li JS, Sexton DJ, Mick N, Nettles R, Fowler VG Jr, Ryan T, Bashore T, Corey GR (2000) Proposed modifications to the Duke criteria for the diagnosis of infective endocarditis. Clin Infect Dis 30(4):633-638

33. Seymour CW, Gesten F, Prescott HC, Friedrich ME, Iwashyna TJ, Phillips GS, Lemeshow S, Osborn T, Terry KM, Levy MM (2017) Time to treatment and mortality during mandated emergency care for sepsis. N Engl J Med 376(23):2235-2244

34. Muller AE, Huttner B, Huttner A (2018) Therapeutic drug monitoring of beta-lactams and other antibiotics in the intensive care unit: which agents, which patients and which infections? Drugs 78(4):439-451

35. Huttner A, Von Dach E, Renzoni A, Huttner BD, Affaticati M, Pagani L, Daali Y, Pugin J, Karmime A, Fathi M, Lew D, Harbarth S (2015) Augmented renal clearance, low beta-lactam concentrations and clinical outcomes in the critically ill: an observational prospective cohort study. Int J Antimicrob Agents 45(4): 385-392

36. Ulldemolins M, Roberts JA, Lipman J, Rello J (2011) Antibiotic dosing in multiple organ dysfunction syndrome. Chest 139(5): $1210-1220$
37. Ferrer R, Artigas A, Levy MM, Blanco J, Gonzalez-Diaz G, Garnacho-Montero J, Ibanez J, Palencia E, Quintana M, de la Torre-Prados MV, Edusepsis Study G (2008) Improvement in process of care and outcome after a multicenter severe sepsis educational program in Spain. JAMA 299(19):2294-2303

38. Levy MM, Dellinger RP, Townsend SR, Linde-Zwirble WT, Marshall JC, Bion J, Schorr C, Artigas A, Ramsay G, Beale R, Parker MM, Gerlach H, Reinhart K, Silva E, Harvey M, Regan S, Angus DC (2010) The Surviving Sepsis Campaign: results of an international guideline-based performance improvement program targeting severe sepsis. Intensive Care Med 36(2):222-231

39. Shapiro NI, Howell MD, Talmor D, Nathanson LA, Lisbon A, Wolfe RE, Weiss JW (2005) Serum lactate as a predictor of mortality in emergency department patients with infection. Ann Emerg Med 45(5):524-528

40. Garcia-Alvarez M, Marik P, Bellomo R (2014) Sepsis-associated hyperlactatemia. Crit Care 18(5):503

41. Holmbom M, Giske CG, Fredrikson M, Ostholm Balkhed A, Claesson C, Nilsson LE, Hoffmann M, Hanberger H (2016) 14year survey in a Swedish County reveals a pronounced increase in bloodstream infections (BSI). Comorbidity - an independent risk factor for both BSI and mortality. PLoS One 11(11):e0166527

42. Esteban A, Frutos-Vivar F, Ferguson ND, Penuelas O, Lorente JA, Gordo F, Honrubia T, Algora A, Bustos A, Garcia G, Diaz-Reganon IR, de Luna RR (2007) Sepsis incidence and outcome: contrasting the intensive care unit with the hospital ward. Crit Care Med 35(5): 1284-1289

43. Goto M, Al-Hasan MN (2013) Overall burden of bloodstream infection and nosocomial bloodstream infection in North America and Europe. Clin Microbiol Infect 19(6):501-509

44. Shapiro N, Howell MD, Bates DW, Angus DC, Ngo L, Talmor D (2006) The association of sepsis syndrome and organ dysfunction with mortality in emergency department patients with suspected infection. Ann Emerg Med 48(5):583-590 590 e581

45. Sanderson M, Chikhani M, Blyth E, Wood S, Moppett IK, McKeever T, Simmonds MJ (2018) Predicting 30-day mortality in patients with sepsis: an exploratory analysis of process of care and patient characteristics. J Intensive Care Soc 19(4):299-304

46. Godfrey G, Pilcher D, Hilton A, Bailey M, Hodgson CL, Bellomo R (2012) Treatment limitations at admission to intensive care units in Australia and New Zealand: prevalence, outcomes, and resource use*. Crit Care Med 40(7):2082-2089

47. Skjaker SA, Hoel H, Dahl V, Stavem K (2017) Factors associated with life-sustaining treatment restriction in a general intensive care unit. PLoS One 12(7):e0181312

Publisher's note Springer Nature remains neutral with regard to jurisdictional claims in published maps and institutional affiliations. 